\title{
Three-Dimensional Finite Element Analysis of Anterior Two-Unit Cantilever Resin-Bonded Fixed Dental Prostheses
}

\author{
Filip Keulemans, ${ }^{1}$ Akikazu Shinya, ${ }^{2,3}$ Lippo V. J. Lassila, ${ }^{2}$ Pekka K. Vallittu, ${ }^{2}$ \\ Cornelis J. Kleverlaan, ${ }^{4}$ Albert J. Feilzer, ${ }^{4}$ and Roeland J. G. De Moor ${ }^{1}$ \\ ${ }^{1}$ Department of Restorative Dentistry and Endodontology, Dental School, Ghent University Hospital, Ghent University, \\ De Pintelaan 185/P8, 9000 Gent, Belgium \\ ${ }^{2}$ Department of Biomaterials Science, BioCity Turku Biomaterials Research Program, Institute of Dentistry, \\ University of Turku, Lemminkäisenkatu 2, 20520 Turku, Finland \\ ${ }^{3}$ Department of Crown and Bridge, School of Life Dentistry at Tokyo, The Nippon Dental University, 1-9-20 Fujimi, \\ Chiyoda-ku, Tokyo 102-8158, Japan \\ ${ }^{4}$ Department of Dental Materials Science, Academic Centre for Dentistry Amsterdam (ACTA), \\ University of Amsterdam and VU University Amsterdam, Mahlerlaan 3004, 1081 LA Amsterdam, Netherlands
}

Correspondence should be addressed to Filip Keulemans; filip.keulemans@ugent.be

Received 15 July 2014; Accepted 21 August 2014

Academic Editor: Samir Nammour

Copyright (C) 2015 Filip Keulemans et al. This is an open access article distributed under the Creative Commons Attribution License, which permits unrestricted use, distribution, and reproduction in any medium, provided the original work is properly cited.

\begin{abstract}
The aim of this study was to evaluate the influence of different framework materials on biomechanical behaviour of anterior twounit cantilever resin-bonded fixed dental prostheses (RBFDPs). A three-dimensional finite element model of a two-unit cantilever RBFDP replacing a maxillary lateral incisor was created. Five framework materials were evaluated: direct fibre-reinforced composite (FRC-Z250), indirect fibre-reinforced composite (FRC-ES), gold alloy (M), glass ceramic (GC), and zirconia (ZI). Finite element analysis was performed and stress distribution was evaluated. A similar stress pattern, with stress concentrations in the connector area, was observed in RBFDPs for all materials. Maximal principal stress showed a decreasing order: ZI $>$ M $>$ GC $>$ FRC-ES $>$ FRCZ250. The maximum displacement of RBFDPs was higher for FRC-Z250 and FRC-ES than for M, GC, and ZI. FE analysis depicted differences in location of the maximum stress at the luting cement interface between materials. For FRC-Z250 and FRC-ES, the maximum stress was located in the upper part of the proximal area of the retainer, whereas, for M, GC, and ZI, the maximum stress was located at the cervical outline of the retainer. The present study revealed differences in biomechanical behaviour between all RBFDPs. The general observation was that a RBFDP made of FRC provided a more favourable stress distribution.
\end{abstract}

\section{Introduction}

Resin-bonded fixed dental prostheses (RBFDPs) have proven to be a reliable treatment alternative for the replacement of missing teeth $[1,2]$ especially in cases where conservation of tooth tissue is needed and limited financial resources are available. According to a recent systematic review, RBFDPs exhibit an estimated survival rate of $87.7 \%$ (95\% confidence interval: $81.6 \%-91.9 \%$ ) after 5 years [3]. Notwithstanding their good clinical performance, the most frequent complication was debonding, with a reported cumulative debonding rate of $19.2 \%$ (95\% CI: $13.8-26.3 \%$ ) after 5 years [3].
The use of more extensive preparation of the abutment teeth, including palatal or lingual coverage with 180-degree wraparound, chamfer, cingulum rests, and proximal guide planes and grooves, is a way to improve the retention of RBFDPs [4]. Another way to minimize debonding is to design RBFDPs as a two-unit cantilever. Several clinical studies of the last decade have demonstrated that two-unit cantilever RBFDPs performed as well as or even better than their threeunit fixed-fixed counterparts [5-11]. Elimination of interfacial stresses, induced by a combination of dynamic tooth contacts and differential movements of the abutment teeth, is the most widely accepted explanation for their successful clinical performance $[4,12]$. 

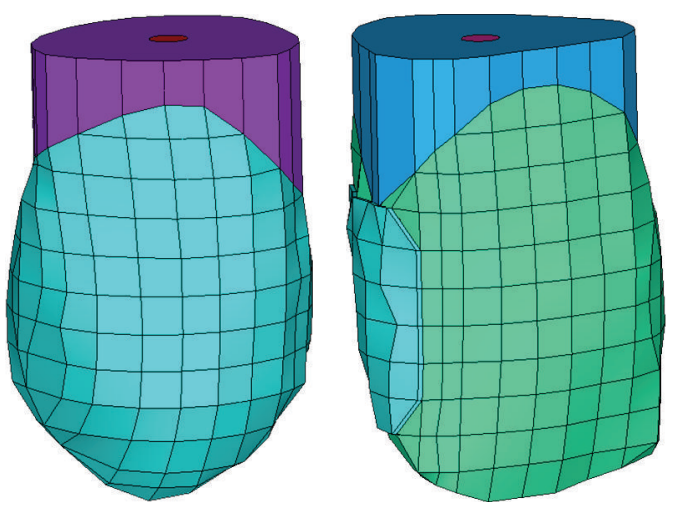

(a)

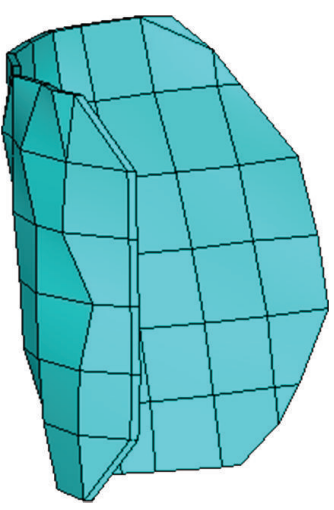

(b)

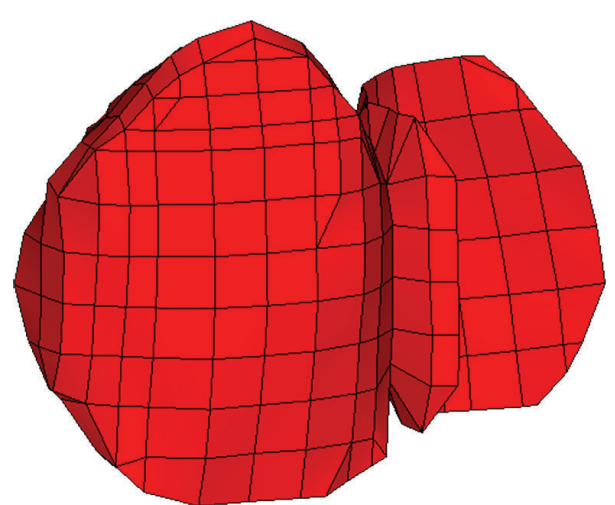

(c)

FIGURE 1: 3D FE model of a cantilever two-unit RBFDP: (a) abutment and adjacent tooth, (b) cement layer, and (c) RBFDP.

The framework of RBFDPs is traditionally made of metal alloys, but their poor aesthetics and the growing awareness towards possible adverse health effects of dental alloys, such as $\mathrm{Ni}-$, $\mathrm{Cr}-$, $\mathrm{Co}-$, $\mathrm{Pd}-$, and $\mathrm{Au}-$-containing alloys [13-17], stimulated the interest in metal-free restorations. Nowadays, allceramic [10] and fibre-reinforced composites (FRC) $[18,19]$ are viable alternatives for framework fabrication of RBFDPs. Some clinical cases reported promising results for all-ceramic RBFDPs [20, 21]. In addition Kern and Sasse reported 10-year survival rates for glass-infiltrated alumina-based RBFDPs of $73.9 \%$ for three-unit fixed-fixed designs and $94.4 \%$ for twounit cantilever designs [11]. The same authors reported a survival rate of $93.3 \%$ after 5 years for single-retainer zirconiabased RBFDPs [22]. Finally, Sailer et al. evaluated the clinical performance of single-retainer lithium disilicate glass ceramic-based RBFDPs finding a 5-year survival rate of $100 \%$ [23]. A recently published systematic review reported for FRC-FDPs a survival rate of 73.4\% (95\% CI: 69.4-77.4\%) after 4.5 years [19]. During a 5-year multicenter clinical study FRC RBFDPs exhibited a survival rate of $64 \%$ [24]. The differences in material properties, especially elastic modulus, adhesive properties, and thermal expansion coefficient, are believed to affect the mechanical and clinical performance of RBFDPs [25]. In order to better understand the failure mechanism of two-unit cantilever RBFDPs, increased knowledge on the biomechanical behaviour of these restorations is needed.

The aim of the present study was to compare, by means of three-dimensional finite element analysis (3DFEA), the biomechanical behaviour of anterior two-unit cantilever RBFDPs made of various framework materials.

\section{Material and Methods}

2.1. Definition of Structures, Geometric Conditions, and Materials. A FE model representing a single tooth gap in the anterior right maxilla, consisting of a central incisor, a missing lateral incisor, and a canine (Figure 1(a)), was created. The central incisor served as the abutment tooth but was not provided with a retainer preparation. The missing lateral incisor was replaced by a two-unit cantilever RBFDP (Figure 1(c)) with a retainer on the central incisor. A wingshaped retainer design, which enwrapped the palatal and distal surface of the abutment tooth, was selected and the pontic was shaped according a modified ridge lap design. Three-dimensional FE model of the cement layer, with a uniform thickness of $100 \mu \mathrm{m}$, is shown in Figure 1(b). A more detailed description of the creation of the FE model was published earlier by Shinya et al. [25].

The geometry of the healthy standard tooth as abutment has been previously described [26]. Not only the natural tooth geometry but also the composition (enamel, dentine, and pulp tissue) was mimicked. Roots under the bone level, periodontal ligaments, and alveolar bone were not created.

Materials properties are derived from clinically used materials (reference brand between parentheses): hybrid particulate filler composite (PFC) for laboratory use (Estenia C\&B; Kuraray medical Inc., Tokyo, Japan), hybrid PFC for chairside use (Filtek Z250; 3M ESPE, MN, USA), unidirectional FRC for laboratory use (Estenia C\&B EG fiber; Kuraray medical Inc., Tokyo, Japan), unidirectional fibre-reinforced composite for direct and chairside use (EverStick C\&B; StickTech Ltd., Turku, Finland), Au-Pd alloy (Olympia; J.F. Jelenko, Armork, NY, USA), lithium disilicate glass ceramic (IPS Empress 2; Ivoclar-Vivadent, Schaan, Liechtenstein), zirconia (InCeram Zirconia; Vita, Bad Säckingen, Germany), feldspathic porcelain (Creation; Klema, Meiningen, Austria), resin-based luting cement (Variolink 2; Ivoclar-Vivadent, Schaan, Liechtenstein), enamel, dentin, and pulp. The material properties, mostly obtained from existing literature, are summarised in Table 1. The materials were assumed to be isotropic, homogeneous, and linear elastic, except for FRC. The mechanical behaviour of continuous unidirectional FRC, influenced by their anisotropic (orthotropic) properties, can be described by 3 young's moduli, 3 Poisson's ratios, and 3 shear moduli [27]. Twenty-node brick element such as solid 95 in ANSYS has the anisotropic material option. The orientation of the element coordinate system was altered in such a way that it matched the fibre direction.

Five different groups with various framework materials were evaluated:

(1) FRC-Z250: a FRC-FDP made of continuous unidirectional E-glass FRC framework (Figure 2) veneered with hybrid PFC for direct and chairside use; 
TABLE 1: Elastic properties of the materials used in the finite element model.

\begin{tabular}{|c|c|c|c|c|}
\hline & $\begin{array}{c}E \text { modulus } \\
(\mathrm{GPa})\end{array}$ & Poisson's ratio & $\begin{array}{l}\text { Shear modulus } \\
(\mathrm{MPa})\end{array}$ & Reference \\
\hline Enamel & 80.0 & 0.30 & - & {$[58]$} \\
\hline Dentin & 17.6 & 0.25 & - & [59] \\
\hline Pulp & 0.002 & 0.45 & - & {$[60,61]$} \\
\hline Resin luting cement & 8.3 & 0.24 & - & {$[62]$} \\
\hline Chairside PFC & 11.5 & 0.31 & - & {$[63,64]$} \\
\hline Laboratory PFC & 22.0 & 0.27 & - & [27] \\
\hline Chairside FRC & & & & $\mathrm{a}$ \\
\hline Longitudinal $(X)$ & 46.0 & 0.39 & 16.5 & \\
\hline Transverse $(Y, Z)$ & 7.0 & 0.29 & 2.7 & \\
\hline Laboratory FRC & & & & {$[27]$} \\
\hline Longitudinal $(X)$ & 39.0 & 0.35 & 14.0 & \\
\hline Transverse $(Y, Z)$ & 12.0 & 0.11 & 5.4 & \\
\hline Lithium disilicate glass ceramic & 96.0 & 0.25 & - & {$[62]$} \\
\hline Zirconia & 205 & 0.22 & - & {$[62]$} \\
\hline Au-Pd alloy & 103 & 0.33 & - & {$[65,66]$} \\
\hline
\end{tabular}

a: data obtained by StickTech Ltd. (Turku, Finland).

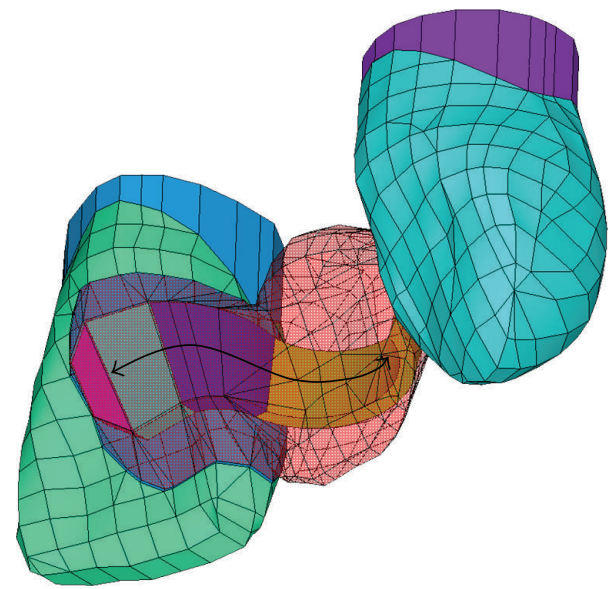

FIGURE 2: 3D FE model of a two-unit cantilever FRC RBFDP: position of the FRC framework in relation to the FDP and the abutment teeth is shown. Double arrowed black line represents the fibre direction.

(2) FRC-ES: a FRC-FDP made of continuous unidirectional E-glass FRC framework veneered with hybrid PFC for laboratory use;

(3) M: a metal-ceramic FDP made of type $3 \mathrm{Au}$-Pd alloy framework veneered with feldspathic porcelain;

(4) GC: an all-ceramic FDP made of lithium disilicate glass ceramic framework veneered with feldspathic porcelain;

(5) ZI: an all-ceramic FDP made of zirconia framework and veneered with feldspathic porcelain.

A FRC framework was designed with thickness of $0.6 \mathrm{~mm}$ and a height of $3.0 \mathrm{~mm}$ [28]. The three-dimensional FE model

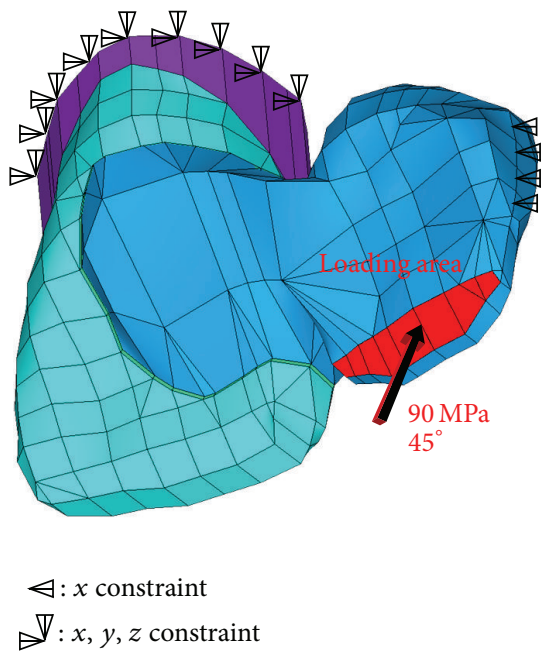

FIGURE 3: Loading and boundary conditions of a 3D FE model representing two-unit cantilever RBFDPs.

of the FRC framework and its position in relation to the RBFDP are shown in Figure 2.

2.2. Mesh Generation, Boundary Conditions, and Data Processing. In order to avoid quantitative differences in stress value, all solid models were derived from a single mapping mesh pattern that generated 103,861 twenty-node brick element (Solid 95 in ANSYS) and 154,784 nodes. Loading and boundary conditions are depicted in Figure 3. A stress of $90 \mathrm{MPa}$ was applied at a $45^{\circ}$ angle to the incisal edge of the pontic. In the present study, the FE model was loaded by applying a stress of $90 \mathrm{MPa}$ in a $45^{\circ}$ angle to the incisal edge of the pontic tooth. An applied stress of $90 \mathrm{MPa}$ to a 


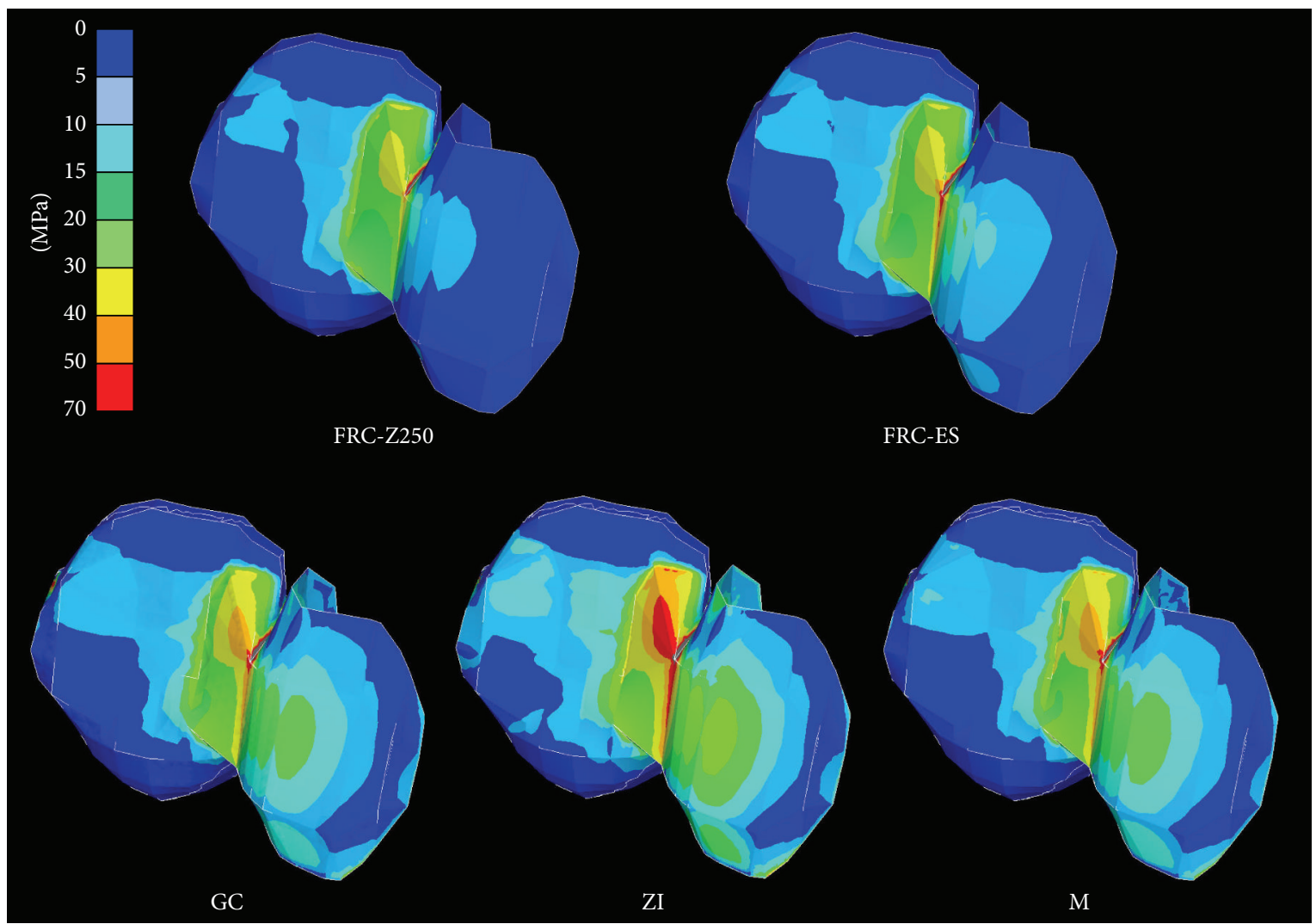

FIGURE 4: Principal stress distribution within two-unit cantilever RBFDPs of various framework materials.

$5.5 \mathrm{~mm}^{2}$ incisal area corresponds to a load of $495 \mathrm{~N}$. The applied load is significantly higher than previously reported maximum anterior mastication loads of 108-382 N [29, 30] and therefore can be regarded as the worst-case scenario. In clinical circumstances, an anterior occlusal contact more closely resembles an area than a point; for that reason it was chosen to apply the load in an area. The terminal elements of the abutment tooth were fixed in all directions, as well as the final elements of the contact area to canine in distal direction. 3DFEA was presumed to be linear static and was performed on PC workstation (Precision Work Station M90, Dell Inc., Texas, USA) using FE analysis software ANSYS 11 (ANSYS Inc.; Houston, TX, USA). The locations and magnitudes of the principal stress $(\mathrm{MPa})$ and displacement $(\mathrm{mm})$ were identified and used for evaluating the biomechanical behaviour. Maximum principal stress describes the highest stress and can be regarded to be a tensile stress.

\section{Results}

3.1. Stresses in the FDP (Figure 4). Differences in maximum principal stress were observed (Table 2) and showed a decreasing order: ZI > M > GC > FRC-ES > FRC-Z250. Stress concentrations were located in the connector area, more precisely at the occlusal embrasure, for all framework materials. However, additional stress concentrations were observed at the contact area with the adjacent tooth for all framework materials and at the mesiocervical edge of the retainer for GC $(20-30 \mathrm{MPa}), \mathrm{M}(30-40 \mathrm{MPa})$, and $\mathrm{ZI}$ (50-70 MPa). Stresses at the contact area with the adjacent tooth were lower for FRC-ES and FRC-Z250 (30-40 MPa) in comparison to GC (50-70 MPa), M, and ZI (>70 MPa).

3.2. Stresses at the Cement-Retainer Interface (Figure 5). Differences in maximal principal stress were also observed (Table 2) at the cement-retainer interface and showed a decreasing order: $\mathrm{ZI}>\mathrm{M}>\mathrm{GC}>$ FRC-ES > FRC-Z250. However, their location differed and was observed in the upper part of the proximal area for FRC-Z250 and FRC-ES, while they were located in a semicircular way around the connector and at the cervical edge of the retainer for M, GC, and ZI.

3.3. Stresses in the Cement Layer (Figure 6). FEA revealed (Table 2 ) only slight differences in maximal principal stress and showed a decreasing order: FRC-Z250 > ZI > FRC-ES > $M>$ GC. They were located in a different area of the cement layer. Highest stress concentrations were located in the upper part of the proximal area for FRC-Z250 and FRC-ES, while they were located at the cervical margin for M, GC, and ZI.

3.4. Stresses on the Abutment Tooth (Figure 7). On the abutment tooth only slight differences in maximal principal stress were observed (Table 2). Highest value was $34.9 \mathrm{MPa}$ for 


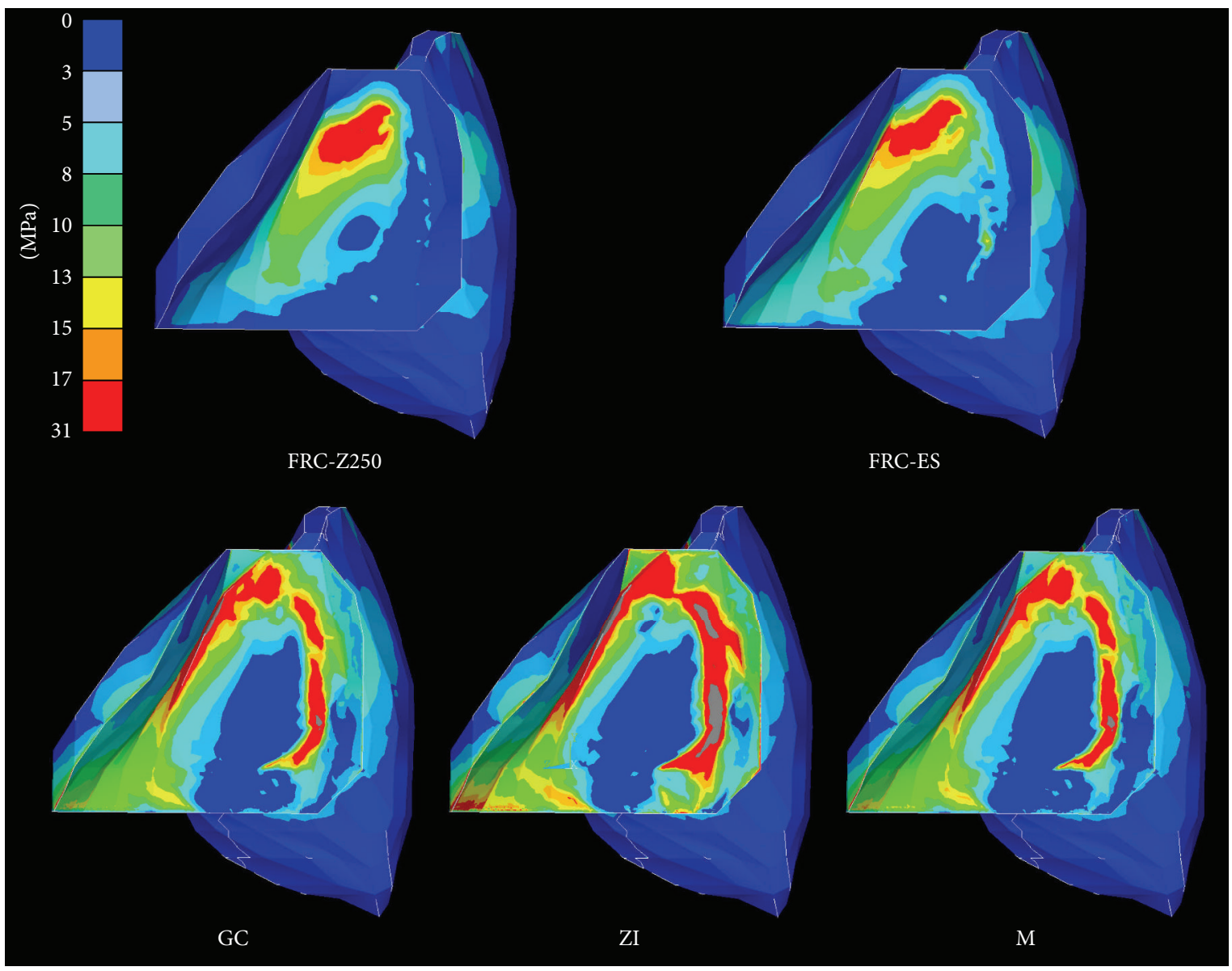

FIGURE 5: Principal stress distribution at the cement-retainer interface for two-unit cantilever RBFDPs of various framework materials.

TABLE 2: Maximum and minimum principal stress (MPa) and displacement (mm) for two-unit cantilever RBFDPs of various framework materials.

\begin{tabular}{lcccccccccrrr}
\hline & & FDP & \multicolumn{4}{c}{ Cement-retainer interface } & \multicolumn{3}{c}{ Cement layer } & \multicolumn{3}{c}{ Abutment tooth } \\
& Max. & Min. & Disp. & Max. & Min. & Disp. & Max. & Min. & Disp. & Max. & Min. & Disp. \\
\hline FRC-Z250 & 156.9 & -56.2 & 0.048 & 17.5 & -5.3 & 0.010 & 31.3 & -7.1 & 0.010 & 34.9 & -7.6 & 0.010 \\
FRC-ES & 177.1 & -67.2 & 0.035 & 23.9 & -9.7 & 0.010 & 27.3 & -7.1 & 0.010 & 30.9 & -9.8 & 0.010 \\
GC & 178.4 & -116.3 & 0.019 & 32.7 & -42.5 & 0.009 & 23.7 & -4.1 & 0.009 & 31.4 & -4.8 & 0.009 \\
ZI & 239.6 & -154.3 & 0.017 & 60.8 & -75.3 & 0.009 & 27.5 & -3.3 & 0.009 & 31.7 & -7.2 & 0.009 \\
M & 197.1 & -149.9 & 0.019 & 36.1 & -45.8 & 0.009 & 24.5 & -3.7 & 0.009 & 31.9 & -5.0 & 0.009 \\
\hline
\end{tabular}

FRC-Z250 and the lowest value was $30.9 \mathrm{MPa}$ for FRCES. Once again, their location showed some differences. Highest stress concentrations for FRC-Z250 and FRC-ES were observed at the upper middle part of the proximal area and were surrounded by a large area of stress concentration (17-31 MPa) that extended towards the palatocervical area, while they were located in a small area of the palatocervical area of the abutment tooth for M, GC, and ZI.

3.5. Displacement (Table 2). Differences in maximum displacement were observed in the pontic part of the RBFDP between the different materials. Higher displacement of the RBFDP was encountered with FRC-Z250 and FRC-ES and then with $\mathrm{M}, \mathrm{GC}$, and ZI. Although, the maximum displacement at the cement-retainer interface, cement layer, and abutment tooth revealed the same trend as those for RBFDPs, a difference of $0.001 \mathrm{~mm}$ between highest and lowest value could not be regarded as clinically relevant.

\section{Discussion}

A static fracture strength test, during which a FDP is vertically loaded till failure, is the most common way to evaluate the mechanical behaviour of FDPs in laboratory conditions [31]. The drawbacks of this approach, such as the difficulty in fabricating uniform FDPs in terms of shape and dimensions, are reckoned by researchers familiar with it. Although, FEA can be regarded as a relatively easy and inexpensive way to 


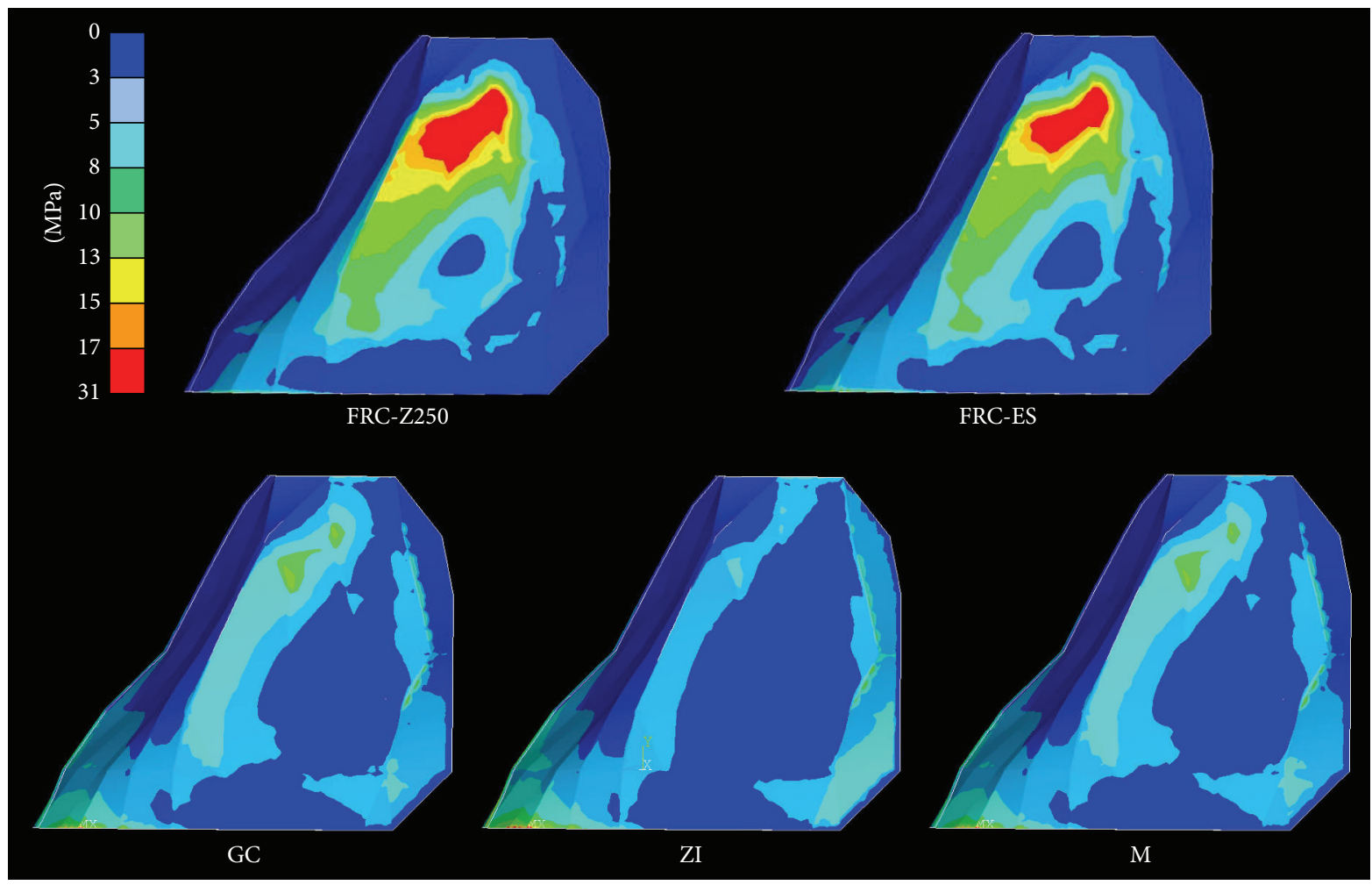

FIGURE 6: Principal stress distribution within the cement layer for two-unit cantilever RBFDPs of various framework materials.

evaluate the mechanical behaviour of complex structures, some limitations should be acknowledged. Some of these limitations can be drawn back to the simplifications made to the finite element models, for example, tooth model without roots, periodontal ligament [32] and, bone, and the assumptions made related to their material properties [33]. The latter were illustrated by the fact that all materials, except FRC, were assumed to be isotropic, homogenous, and linear elastic, despite the anisotropic nature of tooth tissue like dentine [34]. Therefore, one should be aware of the fact that the reported values cannot be regarded as absolute values. The main purpose of this study was to compare the biomechanical behaviour of anterior two-unit cantilever RBFDP made of different framework materials. Nevertheless, the ideal approach is to interpret the results from both FEA and mechanical testing simultaneously, which allows providing more reliable and validated data than either method alone [35]. So mechanical testing on two-unit cantilever RBFDPs in the same condition as this study could be a valuable asset.

In the present study, the FE model was loaded by applying a stress of $90 \mathrm{MPa}$ in a $45^{\circ}$ angle to the incisal edge of the pontic tooth. An applied stress of $90 \mathrm{MPa}$ to a $5.5 \mathrm{~mm}^{2}$ incisal area corresponds to a load of $495 \mathrm{~N}$. The applied load is significantly higher than previously reported maximum anterior mastication loads of 108-382 $\mathrm{N}[29,30]$ and therefore can be regarded as the worst-case scenario. In clinical circumstances, an anterior occlusal contact more closely resembles an area than a point, for that reason it was chosen to apply the load in an area.
Roots, periodontal ligament, and bone, which are responsible for physiologic tooth mobility, were not included in the FE model. Under clinical conditions, a part of the loading is transferred via the roots and the periodontal ligament into the bone. The lack of physiologic tooth mobility in the present FE model negatively influences the outcome of the FEA, in such a way the principal stress values are overestimated. The effect of tooth mobility was illustrated by Rosentritt et al., who found higher fracture strengths for anterior cantilever RBFDPs when luted to abutment teeth with high mobility [36]. Clinically, rationality to use cantilever design over fixedfixed design is related to the teeth mobility. If teeth with increased mobility are involved, risk for debonding of fixedfixed RBFPD from one end is relatively high. A debonded retainer may result in secondary caries that often is not diagnosed in time $[2,4,7]$.

The present FEA revealed differences in biomechanical behaviour between RBFDPs made of different framework materials. Although the location of the stress concentration, observed at the FDP level, was identical for all framework materials, the values differed. The differences in displacement and principal stress can be explained by the differences in elastic modulus between framework materials. RBFDPs made of materials with higher stiffness suffered less displacement, but higher principal stress, than those made of less stiff materials, which can be illustrated by comparison of zirconia and chairside FRC. Zirconia exhibits an elastic modulus of $205 \mathrm{GPa}$ and showed $0.017 \mathrm{~mm}$ displacement and $239.6 \mathrm{MPa}$ maximum principal stress in comparison to $0.048 \mathrm{~mm}$ and 


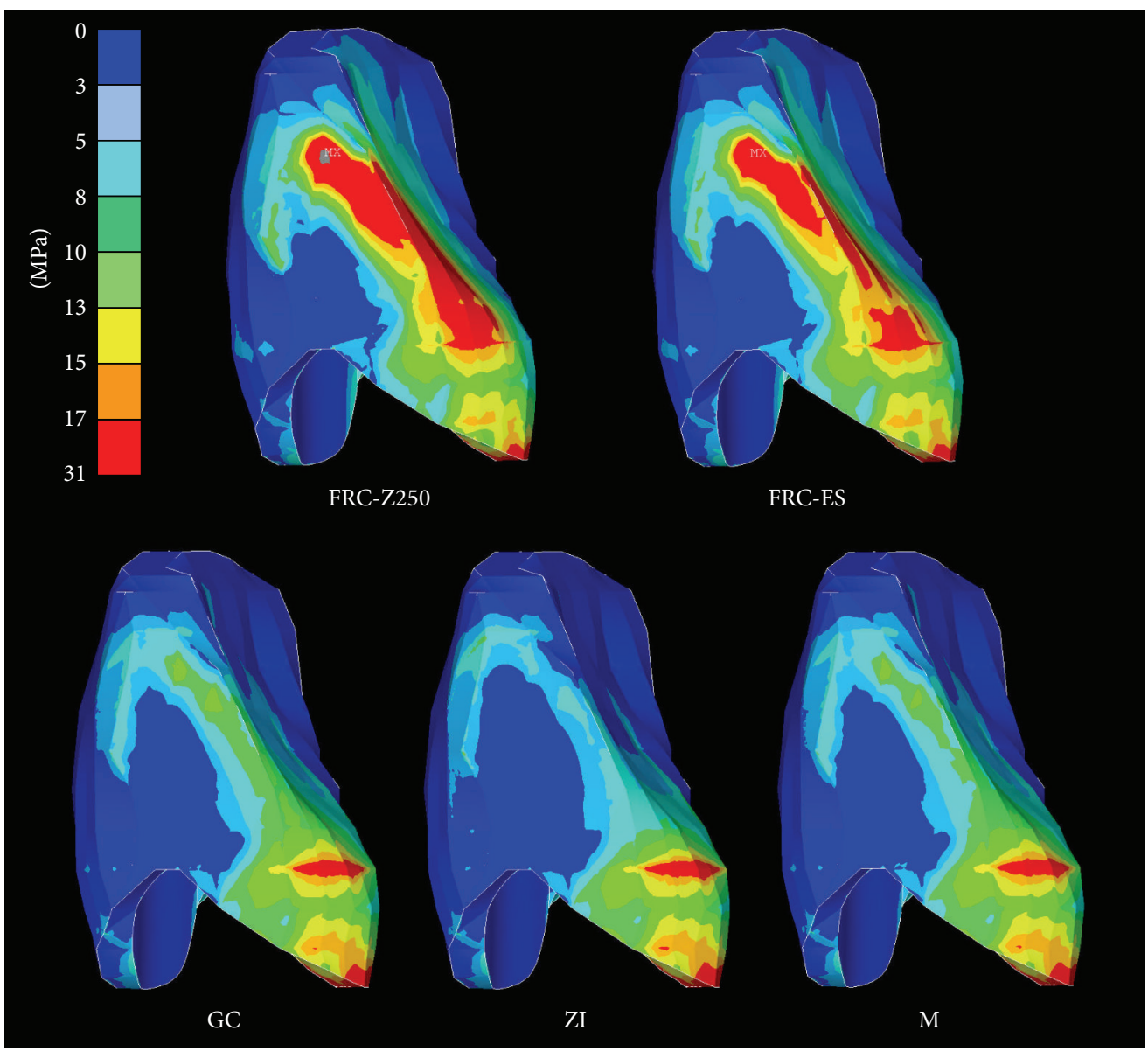

FIGURE 7: Principal stress distribution at the abutment tooth for two-unit cantilever RBFDPs of various framework materials.

156.9 MPa by the chairside FRC with an elastic modulus between $11 \mathrm{GPa}$ (chairside hybrid composite) and $46 \mathrm{GPa}$ (FRC). The highest maximum principal stress was located at the occlusal embrasure of the connector. It has to be noticed that the connector in our FE model was designed with a sharp embrasure and that stresses in this location can be significantly decreased by changing the connector design [37] and its radius of curvature $[37,38]$. Recently, Plengsombut et al. confirmed this finding by revealing a significant lower fracture strength for specimens with a round connector in comparison to those with a sharp connector [39].

A similar situation with regard to stress values was found at the level of cement-retainer interface. Far more interesting were the differences in location between FRC on one hand and M, GC, and ZI on the other hand (Figure 5). A possible explanation is the difference in design between both groups of FDPs. In a FRC-FDP the stiffer fibres acts as a stress dissipater and transfers the stress from the pontic to the central part of the retainer. On the contrary, with FDPs made of a more stiff and uniform framework (M, GC and ZI) the stress is transferred more uniformly through the FDP to an area around the connector and towards the cervical margin of the retainer. Debonding of the FDPs due to early failure of the adhesive interface between retainer and cement layer is likely to be caused by such unfavourable stress location in combination with direct exposure to the oral environment. In particular zirconia, known for its weak adhesion to resin luting cements [40-42], will be prone to adhesive failure.

At the level of the cement layer there was only a slight difference in maximum principal stress values, but as expected the differences in location, as seen at the cement-retainer interface, between FRC on one hand and M, GC, and ZI on the other hand (Figure 6) became more pronounced. It is noteworthy that the cement layer, in the case of M, GC, and $\mathrm{ZI}$, is able to absorb the stresses in the area surrounding the connector and to dissipate them towards the cervical outline. Stress transfer towards unfavourable locations can result in premature failure of the cement layer.

The difference in maximum principal stress value between different framework materials was even lower at the level of the abutment tooth. However, the location of the stress concentration, as depicted in Figure 7, was different. Adhesive failure at the enamel-cement interface is not very likely to occur, as enamel bonding is a reliable procedure with reported values for resin luting cements, like Variolink 2, of 49.3 $\mathrm{MPa}$ [43].

Based on the results of this study the predominant failure mode of two-unit cantilever RBFDPs for each framework material might be predicted. Although acceptable bond strength to resin luting cements can be achieved by glass 
ceramics, their low strength could make them susceptible to connector fracture and therefore probably less suitable for the fabrication of anterior two-unit cantilever RBFDPs. On the contrary, the only clinical study published on cantilever glass ceramic RBFDPs reported $100 \%$ survival after 6-year concluding [23]. Nevertheless, in this study some minor chippings at the pontic were described [23]. There are more studies available on cantilever alumina RBFDPs [11, 44, 45]. These cantilever alumina RBFDPs exhibited a 10-year survival rate of $94.4 \%$ [11]. During their study only one cantilever RBFDP was lost due to fracture of the connector. Koutayas et al. reported connector fracture as the predominant fatigue failure of cantilever alumina RBFDPs [44, 45]. Since glass ceramics exhibit flexural strength of $252 \mathrm{MPa}$ [46], which is inferior to the flexural strength of alumina (429 MPa) [47], and their bond strength to resin luting cements is superior to that of alumina [48], more fractures would be expected with cantilever glass ceramic RBFDPs. A possible explanation is the fact that alumina-based RBFDPs are made of an alumina core veneered with feldspathic porcelain, while lithium disilicate glass ceramic-based RBFDPS can be made from monolithic lithium disilicate. It is known that monolithic ceramic restorations exhibit higher fracture strength than bilayered or veneered ceramic restorations [ 49 , 50].

Although FRC RBFDPs seem to be more promising as they exhibit good bond strength to resin luting cement, connector fracture seems to be the failure mode to be expected. Clinical [51] and in vitro $[52,53]$ findings on FRC RBFDPs also confirm this prediction. Connector fracture in all-ceramic RBFDs results in immediate loss of the pontic resulting in an acute aesthetic problem, while in case of FRC RBFDPs the glass fibres keeps the pontic in place. Nevertheless, they are at the moment only suitable as low cost temporary alternative due to the low strength of the veneering composite. Further improvements can be expected from modified framework designs $[54,55]$ and improved resin composites [56].

Zirconia and metal RBFDPs are suspected to fail most likely because of debonding. A multitude of clinical research on cantilever metal RBFDPs corroborates this prediction [6, $8,9]$, since debonding was reported as the major reason of failure. A metal alloy exhibits plasticity, which can explain this mode of failure. Zirconia, regardless of its high strength, does not seem to be the ideal material for cantilever RBFDPs, due to the unfavourable stress distribution and low bond strength to resin luting cement leading to premature debonding. Only a limited amount of in vitro and in vivo studies on zirconia RBFDPs is available. In vitro studies have shown that minimal invasive cantilever zirconia-based RBFDPs subjected to fatigue loading predominantly failed due to debonding $[36,57]$. However, the same studies showed a decrease in percentage of debonding in favour of retainer fractures, when a more retentive retainer design was used. Although, one should be aware that the high stress concentration at the mesiocervical edge of the retainer indicates (Figure 5) that retainer fracture in those studies is most probably the result of partial debonding. Due to partial debonding more complex torque and bending forces act on the retainer, which results in retainer fracture. The only clinical study on cantilever zirconia-based RBFDPs also reported debonding as major failure [22]. Recent improvement of the adhesive performance of zirconia by selective infiltration etching increased the bond strength to Panavia F2.0 up to $49.8 \mathrm{MPa}$ [42]. The achievement of a strong and durable bond with zirconia-based materials makes it the most promising alternative to metal-based anterior two-unit cantilever RBFDPs.

\section{Conclusions}

Within the limitations of this study, 3DFEA revealed differences in biomechanical behaviour between RBFDPs made of different framework materials.

(1) The general observation was that a RBFDP made of FRC provided a more evenly distributed stress pattern from loading area towards abutment tooth.

(2) Maximum principal stress was located at the occlusal embrasure of the connector for all framework materials: highest value was found for ZI, while the lowest was found for FRC-Z250.

(3) Advanced stress analyses suggest a possible difference in predominant failure mode: connector fracture for FRC- and glass ceramic-based RBFDPs and debonding for metal- and zirconia-based RBFDPs.

(4) A stress concentration was found at the contact area with the adjacent tooth, indicating that the applied load is partially transferred to the adjacent tooth.

\section{Conflict of Interests}

The authors declare that there is no conflict of interests regarding the publication of this paper.

\section{References}

[1] O. El-Mowafy and M. H. M. Rubo, "Resin-bonded fixed partial dentures: a literature review with presentation of a novel approach," International Journal of Prosthodontics, vol. 13, no. 6, pp. 460-467, 2000.

[2] K. A. Durey, P. J. Nixon, S. Robinson, and M. F. W.-Y. Chan, "Resin bonded bridges: techniques for success," The British Dental Journal, vol. 211, no. 3, pp. 113-118, 2011.

[3] B. E. Pjetursson, W. C. Tan, K. Tan, U. Brägger, M. Zwahlen, and N. P. Lang, "A systematic review of the survival and complication rates of resin-bonded bridges after an observation period of at least 5 years," Clinical Oral Implants Research, vol. 19, no. 2, pp. 131-141, 2008.

[4] A. van Dalen, A. J. Feilzer, and C. J. Kleverlaan, "A literature review of two-unit cantilevered FPDs," International Journal of Prosthodontics, vol. 17, no. 3, pp. 281-284, 2004.

[5] M. G. Botelho, A. W. K. Chan, E. Y. L. Yiu, and E. T. P. Tse, "Longevity of two-unit cantilevered resin-bonded fixed partial dentures," The American Journal of Dentistry, vol. 15, no. 5, pp. 295-299, 2002. 
[6] M. G. Botelho, K. C. M. Leung, H. Ng, and K. Chan, "A retrospective clinical evaluation of two-unit cantilevered resinbonded fixed partial dentures," Journal of the American Dental Association, vol. 137, no. 6, pp. 783-788, 2006.

[7] A. W. K. Chan and I. E. Barnes, "A prospective study of cantilever resin-bonded bridges: an intial report," Australian Dental Journal, vol. 45, no. 1, pp. 31-36, 2000.

[8] S. Djemal, D. Setchell, P. King, and J. Wickens, "Long-term survival characteristics of 832 resin-retained bridges and splints provided in a post-graduate teaching hospital between 1978 and 1993," Journal of Oral Rehabilitation, vol. 26, no. 4, pp. 302-320, 1999.

[9] D. L. Hussey and G. J. Linden, "The clinical performance of cantilevered resin-bonded bridgework," Journal of Dentistry, vol. 24, no. 4, pp. 251-256, 1996.

[10] M. Sasse and M. Kern, "All-ceramic resin-bonded fixed dental prostheses: treatment planning, clinical procedures, and outcome," Quintessence International, vol. 45, pp. 291-297, 2014.

[11] M. Kern and M. Sasse, "Ten-year survival of anterior all-ceramic resin-bonded fixed dental prostheses," The Journal of Adhesive Dentistry, vol. 13, no. 5, pp. 407-410, 2011.

[12] M. Botelho, "Resin-bonded prostheses: the current state of development," Quintessence International, vol. 30, no. 8, pp. 525-534, 1999.

[13] G. Schmalz and P. Garhammer, "Biological interactions of dental cast alloys with oral tissues," Dental Materials, vol. 18, no. 5, pp. 396-406, 2002.

[14] J. Muris, R. J. Scheper, C. J. Kleverlaan et al., "Palladium-based dental alloys are associated with oral disease and palladiuminduced immune responses," Contact Dermatitis, vol. 71, no. 2, pp. 82-91, 2014.

[15] S. K. Mallineni, S. Nuvvula, J. P. Matinlinna, C. K. Yiu, and N. M. King, "Biocompatibility of various dental materials in contemporary dentistry: a narrative insight," Journal of Investigative and Clinical Dentistry, vol. 4, no. 1, pp. 9-19, 2013.

[16] A. Faurschou, T. Menné, J. D. Johansen, and J. P. Thyssen, "Metal allergen of the 21st century-a review on exposure, epidemiology and clinical manifestations of palladium allergy," Contact Dermatitis, vol. 64, no. 4, pp. 185-195, 2011.

[17] R. R. Torgerson, M. D. P. Davis, A. J. Bruce, S. A. Farmer, and R. S. Rogers III, "Contact allergy in oral disease," Journal of the American Academy of Dermatology, vol. 57, no. 2, pp. 315-321, 2007.

[18] P. K. Vallittu, "Survival rates of resin-bonded, glass fiberreinforced composite fixed partial dentures with a mean followup of 42 months: a pilot study," Journal of Prosthetic Dentistry, vol. 91, no. 3, pp. 241-246, 2004.

[19] C. C. M. Van Heumen, C. M. Kreulen, and N. H. J. Creugers, "Clinical studies of fiber-reinforced resin-bonded fixed partial dentures: a systematic review," European Journal of Oral Sciences, vol. 117, no. 1, pp. 1-6, 2009.

[20] M. Foitzik, A. M. Lennon, and T. Attin, "Successful use of a single-retainer all-ceramic resin-bonded fixed partial denture for replacement of a maxillary canine: a clinical report," Quintessence International, vol. 38, no. 3, pp. 241-246, 2007.

[21] F. Komine and M. Tomic, "A single-retainer zirconium dioxide ceramic resin-bonded fixed partial denture for single tooth replacement: a clinical report," Journal of Oral Science, vol. 47, no. 3, pp. 139-142, 2005.

[22] M. Sasse and M. Kern, "CAD/CAM single retainer zirconiaceramic resin-bonded fixed dental prostheses: clinical outcome after 5 years," International Journal of Computerized Dentistry, vol. 16, no. 2, pp. 109-118, 2013.

[23] I. Sailer, T. Bonani, U. Brodbeck, and C. H. F. Hämmerle, "Retrospective clinical study of single-retainer cantilever anterior and posterior glass-ceramic resin-bonded fixed dental prostheses at a mean follow-up of 6 years," The International Journal of Prosthodontics, vol. 26, pp. 443-450, 2013.

[24] C. C. M. van Heumen, J. W. V. van Dijken, J. W. Tanner et al., "Five-year survival of 3-unit fiber-reinforced composite fixed partial dentures in the anterior area," Dental Materials, vol. 25, no. 6, pp. 820-827, 2009.

[25] A. Shinya, D. Yokoyama, L. V. J. Lassila, A. Shinya, and P. K. Vallittu, "Three-dimensional finite element analysis of metal and FRC adhesive fixed dental prostheses," Journal of Adhesive Dentistry, vol. 10, no. 5, pp. 365-371, 2008.

[26] R. Wheeler, Dental Anatomy, Phisiology and Oclussion, Saunders, Philadelphia, Pa, USA, 5th edition, 1974.

[27] M. Ootaki, A. Shin-Ya, H. Gomi, and Y. Nakasone, "Optimum design for fixed partial dentures made of hybrid resin with glass fiber reinforcement by finite element analysis: effect of vertical reinforced thickness on fiber frame," Dental Materials Journal, vol. 26, no. 2, pp. 280-289, 2007.

[28] D. Yokoyama, A. Shinya, L. V. J. Lassila et al., "Framework design of an anterior fiber-reinforced hybrid composite fixed partial denture: a 3D finite element study." The International journal of prosthodontics, vol. 22, no. 4, pp. 405-412, 2009.

[29] A. Waltimo and M. Könönen, "Maximal bite force and its association with signs and symptoms of craniomandibular disorders in young Finnish non-patients.," Acta Odontologica Scandinavica, vol. 53, no. 4, pp. 254-258, 1995.

[30] E. Helkimo, G. E. Carlsson, and M. Helkimo, "Bite force and state of dentition.", Acta Odontologica Scandinavica, vol. 35, no. 6, pp. 297-303, 1977.

[31] J. R. Kelly, P. Benetti, P. Rungruanganunt, and A. D. Bona, "The slippery slope-critical perspectives on in vitro research methodologies," Dental Materials, vol. 28, no. 1, pp. 41-51, 2012.

[32] T.-S. Lin, C.-L. Lin, C.-H. Wang, C.-H. Chang, and Y.-H. Chang, "The effect of retainer thickness on posterior resinbanded prostheses: a finite element study," Journal of Oral Rehabilitation, vol. 31, no. 11, pp. 1123-1129, 2004.

[33] S. A. Romeed, S. L. Fok, and N. H. F. Wilson, "Finite element analysis of fixed partial denture replacement," Journal of Oral Rehabilitation, vol. 31, no. 12, pp. 1208-1217, 2004.

[34] J. H. Kinney, S. J. Marshall, and G. W. Marshall, “The mechanical properties of human dentin: a critical review and re-evaluation of the dental literature," Critical Reviews in Oral Biology and Medicine, vol. 14, no. 1, pp. 13-29, 2003.

[35] L. A. Lang, R.-F. Wang, B. Kang, and S. N. White, "Validation of finite element analysis in dental ceramics research," Journal of Prosthetic Dentistry, vol. 86, no. 6, pp. 650-654, 2001.

[36] M. Rosentritt, C. Kolbeck, S. Ries, M. Gross, M. Behr, and G. Handel, "Zirconia resin-bonded fixed partial dentures in the anterior maxilla," Quintessence International, vol. 39, no. 4, pp. 313-319, 2008.

[37] W. Oh, N. Götzen, and K. J. Anusavice, "Influence of connector design on fracture probability of ceramic fixed-partial dentures," Journal of Dental Research, vol. 81, no. 9, pp. 623-627, 2002.

[38] W.-S. Oh and K. J. Anusavice, "Effect of connector design on the fracture resistance of all-ceramic fixed partial dentures," Journal of Prosthetic Dentistry, vol. 87, no. 5, pp. 536-542, 2002. 
[39] K. Plengsombut, J. D. Brewer, E. A. Monaco Jr., and E. L. Davis, "Effect of two connector designs on the fracture resistance of all-ceramic core materials for fixed dental prostheses," Journal of Prosthetic Dentistry, vol. 101, no. 3, pp. 166-173, 2009.

[40] M. InoKoshi, J. De Munck, S. Minakuchi, and B. Van Meerbeek, "Meta-analysis of bonding effectivenes to zirconia ceramics," Journal of Dental Research, vol. 93, pp. 329-334, 2014.

[41] J. Y. Thompson, B. R. Stoner, J. R. Piascik, and R. Smith, "Adhesion/cementation to zirconia and other non-silicate ceramics: where are we now?” Dental Materials, vol. 27, no. 1, pp. 71-82, 2011.

[42] M. N. Aboushelib, C. J. Kleverlaan, and A. J. Feilzer, "Selective infiltration-etching technique for a strong and durable bond of resin cements to zirconia-based materials," Journal of Prosthetic Dentistry, vol. 98, no. 5, pp. 379-388, 2007.

[43] K. Hikita, B. van Meerbeek, J. de Munck et al., "Bonding effectiveness of adhesive luting agents to enamel and dentin," Dental Materials, vol. 23, no. 1, pp. 71-80, 2007.

[44] S. O. Koutayas, M. Kern, F. Ferraresso, and J. R. Strub, "Influence of framework design on fracture strength of mandibular anterior all-ceramic resin-bonded fixed partial dentures," International Journal of Prosthodontics, vol. 15, no. 3, pp. 223-229, 2002.

[45] S. O. Koutayas, M. Kern, F. Ferraresso, and J. R. Strub, "Influence of design and mode of loading on the fracture strength of allceramic resin-bonded fixed partial dentures: an in vitro study in a dual-axis chewing simulator," The Journal of Prosthetic Dentistry, vol. 83, no. 5, pp. 540-547, 2000.

[46] J. Chai, F. C. S. Chu, T. W. Chow, and B. M. H. Liang, "Chemical solubility and flexural strength of zirconia-based ceramics," International Journal of Prosthodontics, vol. 20, no. 6, pp. 587595, 2007.

[47] J. Tinschert, D. Zwez, R. Marx, and K. J. Anusavice, "Structural reliability of alumina-, feldspar-, leucite-, mica- and zirconiabased ceramics," Journal of Dentistry, vol. 28, no. 7, pp. 529-535, 2000.

[48] B.-K. Kim, H. E.-K. Bae, J.-S. Shim, and K.-W. Lee, "The influence of ceramic surface treatments on the tensile bond strength of composite resin to all-ceramic coping materials," Journal of Prosthetic Dentistry, vol. 94, no. 4, pp. 357-362, 2005.

[49] S. Schultheis, J. R. Strub, T. A. Gerds, and P. C. Guess, "Monolithic and bi-layer CAD/CAM lithium-disilicate versus metalceramic fixed dental prostheses: comparison of fracture loads and failure modes after fatigue," Clinical Oral Investigations, vol. 17, no. 5, pp. 1407-1413, 2013.

[50] A. M. Altamimi, A. P. Tripodakis, G. Eliades, and H. Hirayama, "Comparison of fracture resistance and fracture characterization of bilayered zirconia/ fluorapatite and monolithic lithium disilicate all ceramic crowns," International Journal of Esthetic Dentistry, vol. 9, pp. 98-110, 2014.

[51] G. Culy and M. J. Tyas, "Direct resin-bonded, fibre-reinforced anterior bridges: a clinical report," Australian Dental Journal, vol. 43, no. 1, pp. 1-4, 1998.

[52] W. Li, M. V. Swain, Q. Li, J. Ironside, and G. P. Steven, "Fibre reinforced composite dental bridge: part I: experimental investigation," Biomaterials, vol. 25, no. 20, pp. 4987-4993, 2004.

[53] M. Özcan, O. Kumbuloglu, and A. User, "Fracture strength of fiber-reinforced surface-retained anterior cantilever restorations," International Journal of Prosthodontics, vol. 21, no. 3, pp. 228-232, 2008.

[54] F. Keulemans, L. V. J. Lassila, S. Garoushi, P. K. Vallittu, C. J. Kleverlaan, and A. J. Feilzer, "The influence of framework design on the load-bearing capacity of laboratory-made inlayretained fibre-reinforced composite fixed dental prostheses," Journal of Biomechanics, vol. 42, no. 7, pp. 844-849, 2009.

[55] Q. Xie, L. V. J. Lassila, and P. K. Vallittu, "Comparison of load-bearing capacity of direct resin-bonded fiber-reinforced composite FPDs with four framework designs," Journal of Dentistry, vol. 35, no. 7, pp. 578-582, 2007.

[56] S. Garoushi, P. K. Vallittu, and L. V. J. Lassila, "Short glass fiber reinforced restorative composite resin with semi-inter penetrating polymer network matrix," Dental Materials, vol. 23, no. 11, pp. 1356-1362, 2007.

[57] M. Rosentritt, S. Ries, C. Kolbeck, M. Westphal, E.-J. Richter, and G. Handel, "Fracture characteristics of anterior resinbonded zirconia-fixed partial dentures," Clinical Oral Investigations, vol. 13, no. 4, pp. 453-457, 2009.

[58] R. G. Craig, F. A. Peyton, and D. W. Johnson, "Compressive properties of enamel, dental cements, and gold," Journal of Dental Research, vol. 40, pp. 936-945, 1961.

[59] R. G. Craig and F. A. Peyton, "Elastic and mechanical properties of human dentin," Journal of Dental Research, vol. 37, no. 4, pp. 710-718, 1958.

[60] J. W. Farah and R. G. Craig, "Finite element stress analysis of a restored axisymmetric first molar," Journal of Dental Research, vol. 53, no. 4, pp. 859-866, 1974.

[61] A. K. Aydin and A. E. Tekkaya, "Stresses induced by different loadings around weak abutments," The Journal of Prosthetic Dentistry, vol. 68, no. 6, pp. 879-884, 1992.

[62] P. Magne, N. Perakis, U. C. Belser, and I. Krejci, "Stress distribution of inlay-anchored adhesive fixed partial dentures: a finite element analysis of the influence of restorative materials and abutment preparation design," Journal of Prosthetic Dentistry, vol. 87, no. 5, pp. 516-528, 2002.

[63] S. M. Chung, A. U. J. Yap, W. K. Koh, K. T. Tsai, and C. T. Lim, "Measurement of Poisson's ratio of dental composite restorative materials," Biomaterials, vol. 25, no. 13, pp. 2455-2460, 2004.

[64] J. D. Eick, S. P. Kotha, C. C. Chappelow et al., "Properties of silorane-based dental resins and composites containing a stressreducing monomer," Dental Materials, vol. 23, no. 8, pp. 10111017, 2007.

[65] H. F. Morris, "Veterans administration cooperative studies project no. 147/242. Part VII: the mechanical properties of metal ceramic alloys as cast and after simulated porcelain firing," The Journal of Prosthetic Dentistry, vol. 61, no. 2, pp. 160-169, 1989.

[66] K. J. Anusavice, B. Hojjatie, and P. H. Dehoff, "Influence of metal thickness on stress distribution in metal-ceramic crowns," Journal of Dental Research, vol. 65, no. 9, pp. 1173-1178, 1986. 


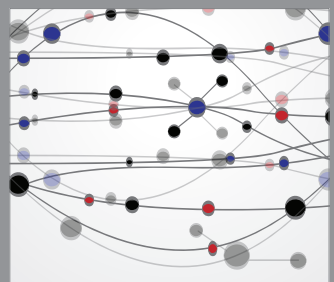

The Scientific World Journal
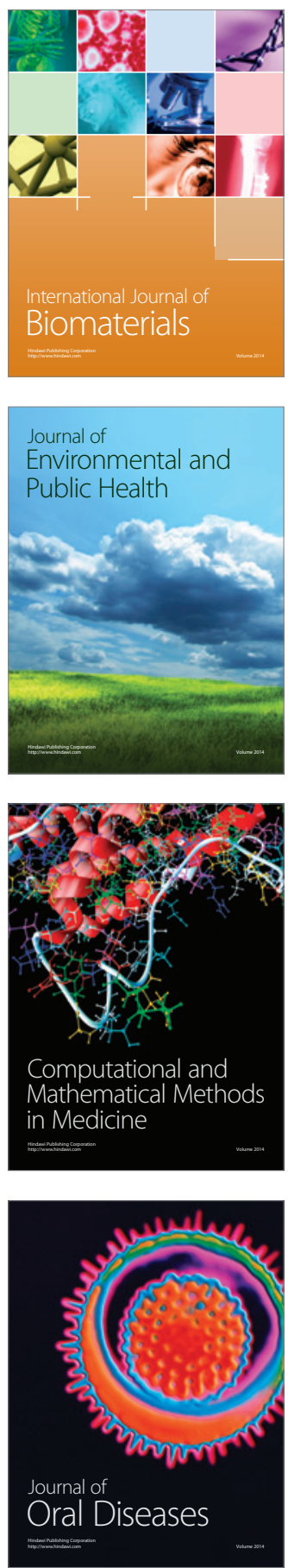
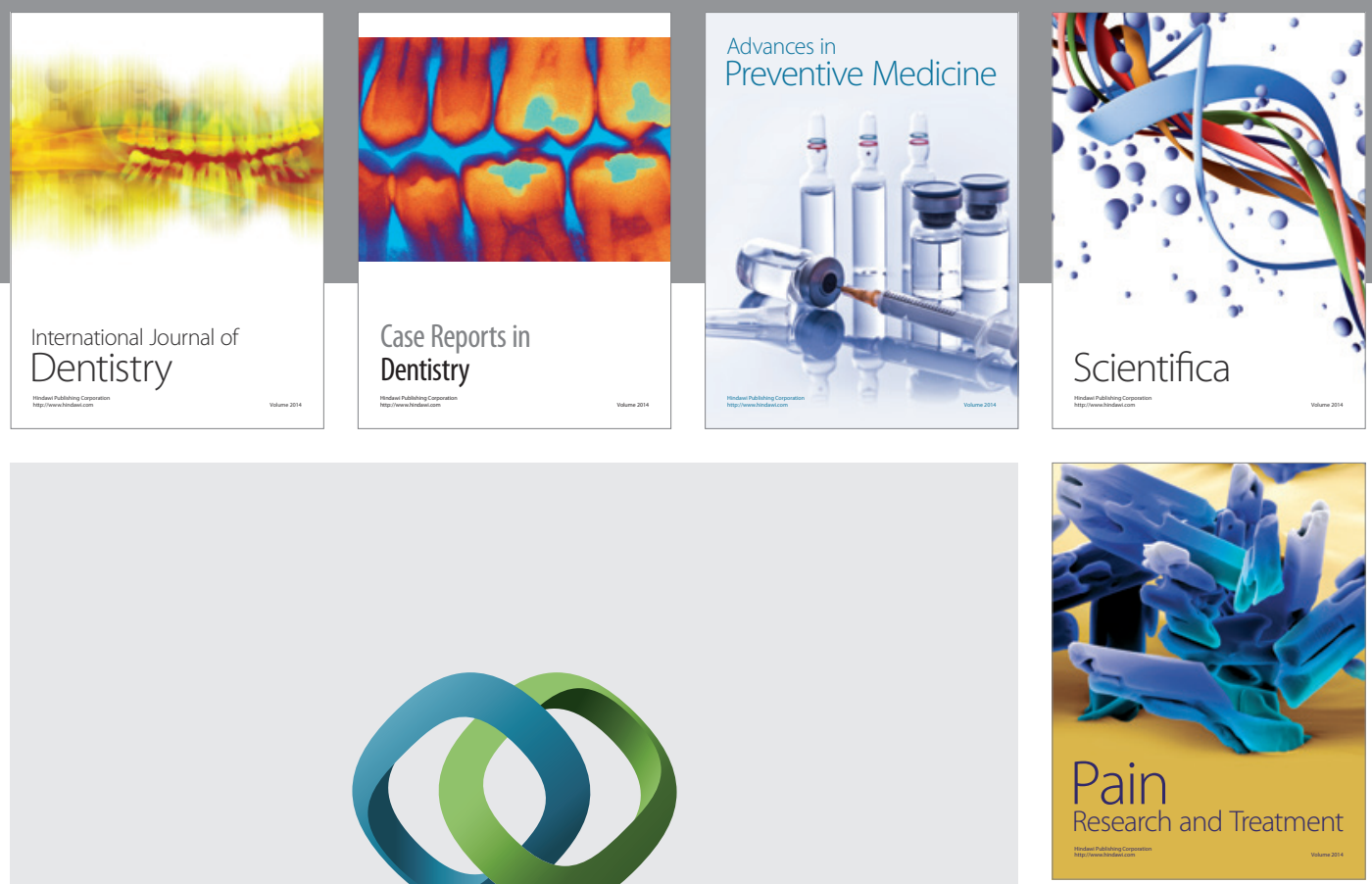

\section{Hindawi}

Submit your manuscripts at

http://www.hindawi.com
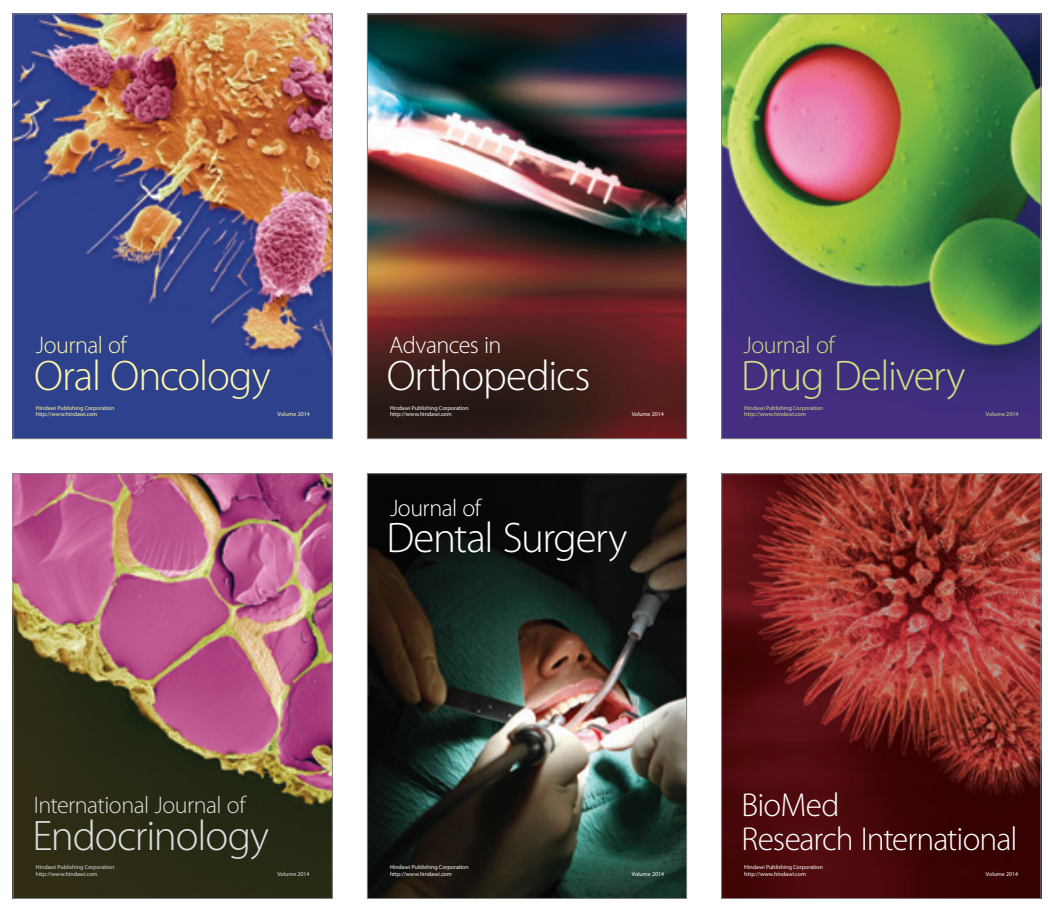

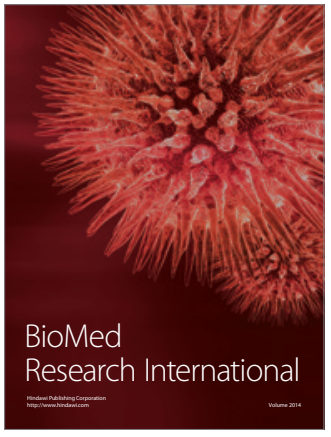

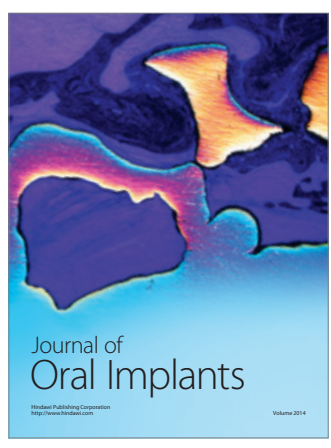
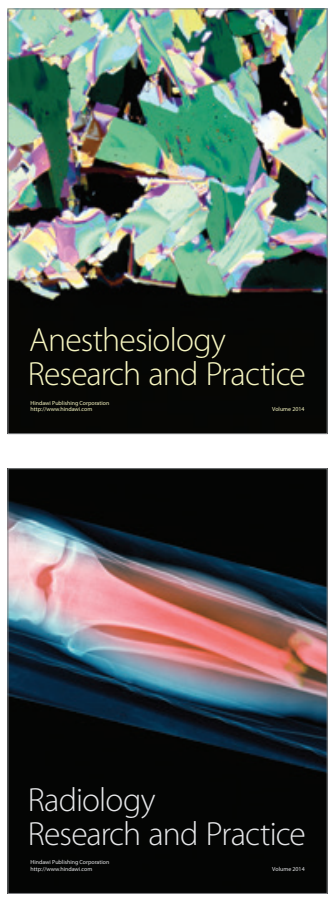